\title{
Management of advanced hepatocellular carcinoma: review of current and potential therapies
}

\author{
Asmaa Gomaa, Imam Waked \\ Hepatology Department, National Liver Institute, Menoufiya University, Shebeen El-Kom 32111, Egypt.
}

Correspondence to: Dr. Asmaa Gomaa, National Liver Institute, Menoufiya University, Shebeen El-Kom 32111, Egypt. E-mail: aibrahim@liver-eg.org

How to cite this article: Gomaa A, Waked I. Management of advanced hepatocellular carcinoma: review of current and potential therapies. Hepatoma Res 2017;3:112-22.

Article history:

Received: 17-01-2017

Accepted: 27-04-2017

Published: 15-06-2017

Key words:

Hepatocellular carcinoma,

advanced stage,

molecular targeted agents,

sorafenib,

immune therapy

\begin{abstract}
Over the past few years, despite improvement in screening and diagnosis of hepatocellular carcinoma (HCC), advanced stage remains the most common presentation at diagnosis, with limited management options, especially options available to patients in limited resource countries. There is currently no effective systemic chemotherapy, targeted, or immunologic therapy for advanced stage HCC. Sorafenib is the only approved front-line moleculartargeted treatment, with slight survival benefit. Regorafenib has recently been approved as second line therapy for HCC after failure of sorafenib. Ongoing research on molecular agents targeting different pathways, combination therapies, and immunotherapy, represent hope for new treatment modalities. This manuscript reviews current treatment, ongoing research, and potential future treatments for advanced HCC.
\end{abstract}

\section{INTRODUCTION}

Hepatocellular carcinoma (HCC) is the second leading cause of cancer-related death globally, with about 800,000 deaths every year. ${ }^{[1]}$ Unfortunately, considerable number of patients are diagnosed at advanced stage unsuitable for surgery or local treatment with poor prognosis and a median overall survival (OS) of about 6 months. Molecular targeted therapies have demonstrated promising efficacy in the management of cancer. Sorafenib improves survival with median OS rate of 6.5-10.7 months, ${ }^{[2]}$ with significant benefit in time to progression, despite the absence of objective response. Numerous trials are ongoing in search for other molecular agents that are more effective than sorafenib, or combinations of therapy that might improve response and survival rates in patients with advanced HCC. Results of trials with lenvatinib as first-line or regorafenib as second line treatments are promising. ${ }^{[3]}$ Radioembolisation is as safe and effective in advanced-stage HCC as first-line or second-line therapy. ${ }^{[4]}$ In addition, the use of immunotherapy in clinical trials demonstrated promising results. ${ }^{[5]}$ This manuscript reviews the current treatments and ongoing research for therapy of advanced HCC.

\section{ADVANCED HCC}

Despite advances in screening and diagnosis, most

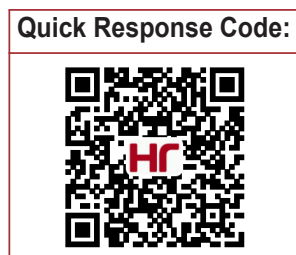


patients with $\mathrm{HCC}$ are diagnosed with advanced disease [Barcelona Clinic Liver Cancer (BCLC) stage $\mathrm{C}$ ], unsuitable for surgery or loco-regional curative treatment. Prognosis of advanced $\mathrm{HCC}$ is poor, and the 1-, 2- and 3-year survival rates are $29 \%, 16 \%$, and $8 \%$, with median OS less than 6 months. ${ }^{[6]}$ This is even less in low and middle income countries, where resources and access to therapy are limited.

In the BRIDGE study that included data for 18,031 patients with $\mathrm{HCC}$ from 42 sites in 14 countries in Asia, Europe and North America, more than $50 \%$ of cases were diagnosed in advanced and terminal stages. ${ }^{[7]}$ Whereas $12 \%$ of HCC patients in Japan and $17 \%$ in Taiwan present in advanced stage HCC (BCLC stage C) and only $1-2 \%$ in terminal stage (BCLC D), between $50 \%$ and $60 \%$ of HCC patients in North America, Europe, China and South Korea present in BCLC stages $C$ and D. ${ }^{[7]}$

The proportion of HCC patients presenting in advanced stages is even larger in limited resource countries. A study that included $2,566 \mathrm{HCC}$ patients from 21 tertiary referral centers in 9 African countries showed that only $23 \%$ presented in early and intermediate stages (BCLC A and B), 49\% in advanced stage (BCLC C) and $28 \%$ in BCLC stage D. The proportion of patients diagnosed with HCC while in advanced or terminal stage was much larger in sub-Saharan countries, with $95 \%$ of the patients diagnosed in BCLC stages $C$ and $\mathrm{D}$, and $97 \%$ of 1,315 patients with $\mathrm{HCC}$ did not receive HCC specific therapy because of advanced stage and unavailability of therapy. ${ }^{[8]}$

This highlights the importance of developing effective therapies for advanced HCC, and that these therapies should be made available and affordable in limited resource countries where most patients present in advanced stage (especially sub-Saharan Africa). This also emphasizes the importance of screening programs for detection of HCC in early treatable stages.

\section{SYSTEMIC THERAPIES}

\section{Molecular targeted therapy}

Advanced HCC has experienced the most relevant advancements in research in HCC lately. Hepatocarcinogenesis is associated with genetic and epigenetic alterations that eventually lead to an alteration in the molecular pathways, leading to uncontrolled growth of the hepatocytes. ${ }^{[9]}$

\section{Sorafenib}

Sorafenib inhibits the serine-threonine kinases Raf-
1 and B-Raf and the activity of vascular endothelial growth factor receptors (VEGFRs) 1, 2, and 3 and platelet-derived growth factor receptor $\beta$ (PDGFR- $\beta$ ). Also it induces down-regulation of anti-apoptotic proteins, leading to significant enhancement of the cytotoxicity of tumor necrosis factor-related apoptosis inducing ligand (TRAIL) to HCC cells. ${ }^{[10]}$

Sorafenib improves survival compared to placebo, with median OS of 6.5-10.7 months, with significant benefit in time to progression (TTP). Many molecular agents have been studied, but only the sorafenib showed efficacy in terms of OS and TTP, based on results of two phase III, randomized controlled studies ${ }^{[2,11]}$ and confirmed in other clinical trials comparing sorafenib to other molecules, ${ }^{[12-16]}$ as well as in real life clinical practice. $^{[17,18]}$

Despite the approval of sorafenib in advanced-stage HCC, several issues remain not known. An important concern is to identify patients who will most probably benefit from sorafenib, to avoid unnecessary toxicity in patients who will not. Several markers at baseline or during treatment, as vascular endothelial growth factor, angiopoietin-2, hepatocyte growing factor, c-Kit or alfafeto-protein (AFP) have been shown to predict OS, but not response to sorafenib in patients with advanced $\mathrm{HCC}^{[19]}$

Several reports showed that the development of some adverse events as dermatological adverse events, ${ }^{[20-22]}$ diarrhea, ${ }^{[23]}$ or arterial hypertension ${ }^{[24]}$ are associated with favorable outcomes. Patients who develop early dermatological adverse events within the first 2 months after starting sorafenib experienced a longer median OS, comparing to those who did not develop this adverse event (18.2 vs. 10.1 months, respectively). ${ }^{[2]}$ Hence, it is mandatory to closely follow the patients and to adjust the dose if needed to avoid unnecessary interruption of the drug in a probably responding patient.

Using sorafenib in patients with Child-Pugh B cirrhosis is challenging. Sorafenib was effective in ChildPugh class B patients as class A patients in terms of progression free survival (PFS), but with lower OS. The median OS was 5.5 months for Child class $B$ patients compared to 11.3 months for Child A patients. ${ }^{[25]}$ The prospective GIDEON trial confirmed that the median OS was shorter in Child-Pugh class B patients, 5.2 months compared to 13.6 months in Child $A$, although the TTP and the incidence of adverse events of sorafenib was similar across subgroups, Child-Pugh class $B$ patients experienced more serious adverse events. The liver dysfunction in advanced cirrhosis may 
impair the effect of sorafenib on tumor progression and interfere with possible survival improvement. ${ }^{[18]}$

Eventually $60-70 \%$ of patients with advanced HCC progress on sorafenib. The pattern of progression on sorafenib has been identified as a predictor of postprogression survival. ${ }^{[26,27]}$ The development of new extra-hepatic lesion, vascular invasion, and worsening performance status on therapy were associated with the poorest prognosis.

For patients in advanced-stage who progress on or cannot tolerate sorafenib, management options are limited, and a large unmet need still exists. However, results of trials with lenvatinib as first line therapy ${ }^{[28]}$ and regorafenib ${ }^{[29]}$ and immunotherapy as effective second line treatments are promising.

\section{Other molecular targeted agents}

\section{First-line therapy}

Sorafenib remains the only approved first line therapy with advanced-stage (BCLC-C) HCC. None of the other targeted agents: the anti-angiogenic tyrosine kinase inhibitors (TKI) sunitinib, ${ }^{[12]}$ linifanib, ${ }^{[15]}$ brivanib, ${ }^{[13]}$ dovitinib ${ }^{[16]}$ or the combination of sorafenib with erlotinib $^{[14]}$ were found superior compared to sorafenib in phase II and III trials as first line therapies in patients with advanced $\mathrm{HCC}$, and none have exceeded the benefits of sorafenib [Figure 1, Supplementary Table 1].

Lenvatinib, on the other hand, is showing promising results as first line therapy in advanced HCC. ${ }^{[3]}$ Lenvatinib is an oral TKI that targets VEGFR1-3, fibroblast growth factor receptor (FGFR)1-4, rearranged during transfection (RET), receptor tyrosine kinase (KIT), and PDGFR and is approved for radioactive iodine-refractory thyroid cancer. A multicenter, openlabel, phase I/II study of lenvatinib, including 46 patients with advanced HCC. Tumor response and stable disease were found in $37 \%$ and $45.7 \%$, respectively, with median TTP of 12.8 months and median OS of 18.7 months. The most common adverse events observed with lenvatinib were hypertension, diarrhea, anorexia, weight loss, and fatigue. ${ }^{[30]}$

Lenvatinib was investigated as first line therapy compared to sorafenib in a multicenter, randomized, open-label, phase III trial that included 954 patients with intermediate or advanced stage HCC. The OS with lenvatinib was non-inferior to sorafenib, and PFS, TTP, and objective response rate (ORR) significantly improved with lenvatinib (NCT01761266). ${ }^{[31]}$ Lenvatinib thus is the first agent to show results that are equal or better than sorafenib in advanced stage HCC, and might become an alternative to sorafenib as first line treatment.

\section{Second-line therapy}

Figure 2 shows OS of second line therapies compared to sorafenib. ${ }^{[2,32-34]}$ Regorafenib, a multi-kinase inhibitor of VEGFR1-3, tyrosine kinase with immunoglobulinlike and EGF-like domains 2 (TIE2), PDGFR $\beta$, FGFR, $\mathrm{KIT}, \mathrm{RET}$, rapidly accelerated fibrosarcoma (RAF), is approved for metastatic colorectal cancer and advanced GI stroma tumors. ${ }^{[35,36]}$ It is the first agent to provide survival benefit after failure of sorafenib in a phase III trial and has recently been approved as second line therapy for HCC. The study included 573 patients who had progressed on sorafenib and it improved OS with a hazard ratio of $0.63(P<0.0001)$; the median OS was 10.6 months for regorafenib vs. 7.8 months for placebo and the disease control rate (DCR) was $65.2 \%$ vs. $36.1 \%(P<0.001) .{ }^{[29]}$

Ongoing studies are evaluating the efficacies [tyrosineprotein kinase Met or hepatocyte growth factor receptor (HGFR)] (c-MET) inhibitors in advanced HCC. A multicenter, randomized, placebo-controlled phase II trial evaluating tivantinib, a selective c-MET inhibitor, included patients with advanced HCC

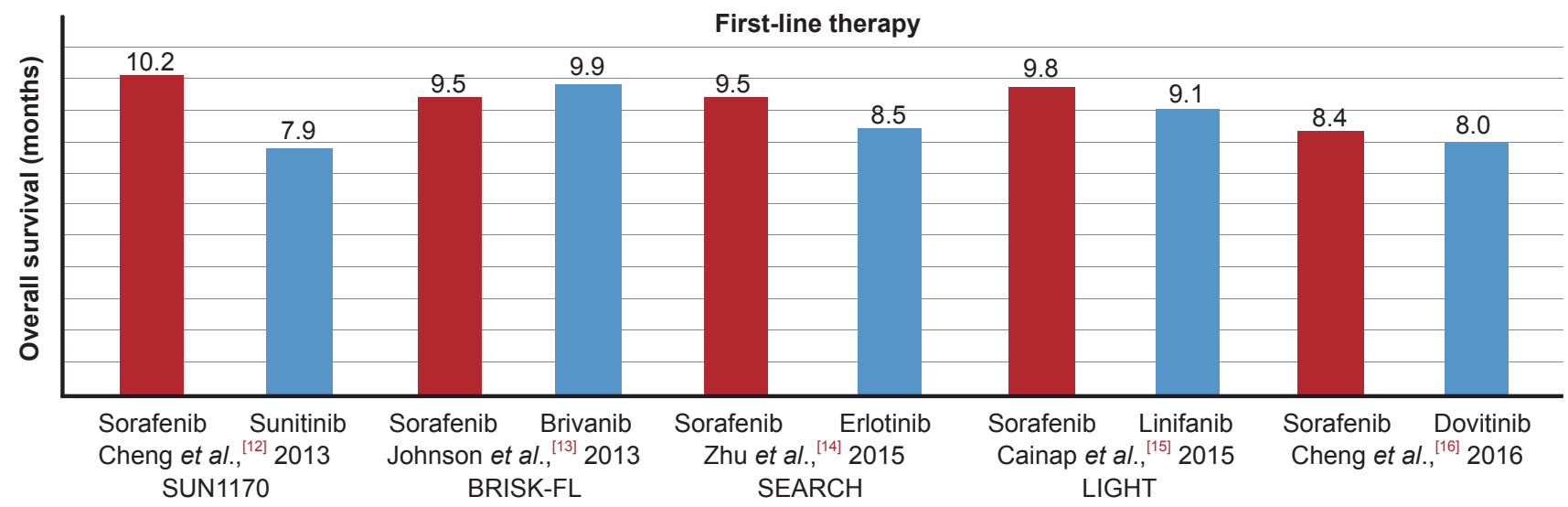

Figure 1: Overall survival in trials of first-line therapy vs. sorafenib for advanced hepatocellular carcinoma 


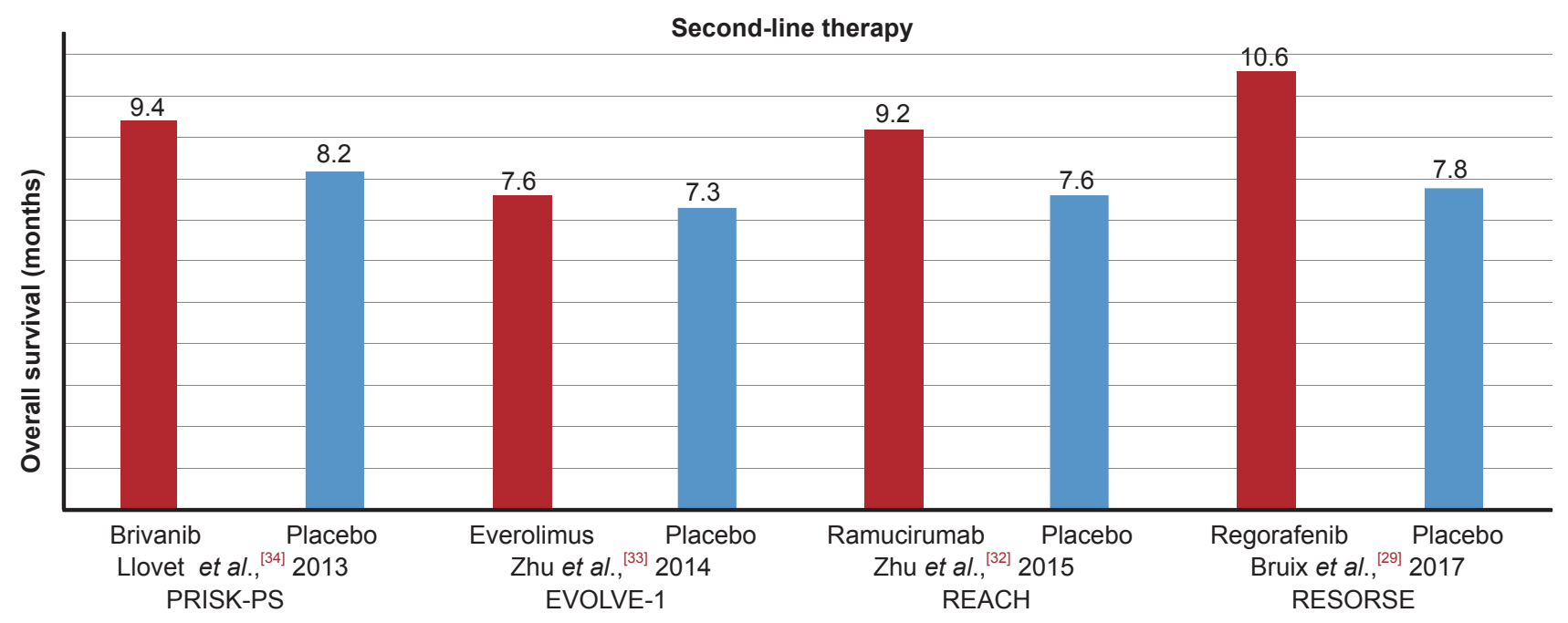

Figure 2: Overall survival in trials of second-line therapy after progression on sorafenib vs. placebo for advanced hepatocellular carcinoma

and compensated cirrhosis, who were refractory or intolerant to sorafenib. Patients treated with tivantinib showed longer TTP than with placebo (1.6 vs. 1.4 months, hazard ratio (HR) $0.64,90 \% \mathrm{Cl} 0.43-0.94, P$ $=0.04$ ) with DCR of $20 \% \cdot{ }^{[37]}$ Patients with high c-met expression showed better OS, and prolonged TTP on tivantinib (OS was 7.2 vs. 3.8 months, $P=0.01$ ), and the DCR increased to $50 \%{ }^{\left[{ }^{37]}\right.} \mathrm{A}$ phase III trial testing tivantinib as second line treatment is ongoing based on better outcome observed in patients with high c-met expression (NCT01755767). Other c-MET inhibitors as foretinib, tepotinib, capmatinib, golvantinib and emibetuzumab are also under investigations.

Ramucirumab, an anti VEGFR monoclonal antibody approved as 2nd line treatment for advanced gastric adenocarcinoma and metastatic lung cancer, was evaluated vs. placebo in a phase III trial as second line treatment in patients with $\mathrm{HCC}$ who progressed or were intolerant to sorafenib (REACH study). It demonstrated significant improvement in OS and DCR. ${ }^{[32]}$ Subgroup analysis showed the survival benefit was limited to patients with baseline AFP $\geq 400 \mathrm{ng} / \mathrm{mL}$ (median OS 7.8 months with ramucirumab vs. 4.2 months in the placebo group). ${ }^{[38]}$ Patients Child-Turcotte-Pugh (CTP) score 5 had better overall response to treatment than patients with CTP scores 6-8, and among those with elevated AFP $\geq 400 \mathrm{ng} / \mathrm{mL}$, improvement with therapy was limited to patients with CTP score 5 and 6 and not in patients with CTP score 7-8 (who experienced higher incident of treatment related grade 3 or higher adverse events). ${ }^{[39]}$ The phase III REACH-2 trial will evaluate ramucirumab as second-line therapy in patients with advanced HCC and elevated AFP (NCT02435433).

Mammalian target for rapamycin (mTOR) inhibitors in phase $\mathrm{I} / \mathrm{II}$ studies showed activity in patients with advanced or recurrent $\mathrm{HCC}{ }^{[40]}$ However, in a phase III study (EVOLVE-1) everolimus did not improve OS in patients with advanced HCC who had failed or were intolerant to sorafenib (median OS, 7.6 months with everolimus, 7.3 months with placebo; HR $1.05 ; 95 \% \mathrm{Cl}$ $0.86-1.27 ; P<0.68) .^{[33]}$

Axitinib, a potent and selective inhibitor of VEGFRs 1-3, was investigated as second-line therapy for HCC in a randomized phase II study compared to placebo. Longer PFS $(P=0.004)$ and TTP $(P=0.006)$ was observed in patients treated with axitinib compared to placebo. However, no improvement in OS was detected. ${ }^{[41]}$

Apatinib, a selective VEGFR-2 tyrosine kinase inhibitor, in a multicenter, randomized, open-label, phase II trial showed potential survival benefit in patients with advanced stage HCC with Child-Pugh class A liver function at either $850 \mathrm{mg} / \mathrm{qd}$ or $750 \mathrm{mg} / \mathrm{qd}$. Apatinib was well tolerated and the main $\mathrm{AE}$ were elevated aminotransferases, thrombocytopenia, leukocytopenia, hyperbilirubinemia, hypertension, hand-foot syndrome and fatigue. ${ }^{[42]}$ Apatinib is being evaluated as second line therapy in patients with advanced HCC who have progressed on, or were intolerant to, sorafenib (NCT027720290), and other anti-angiogenic agents are in very early-stages of development [Supplementary Table 2].

\section{Combination of different molecular targeted therapies}

Inhibition of a single signaling pathway may induce feedback activation of other pathways, hence, combination of different molecularly targeted agents possibly induces synergistic beneficial activity. ${ }^{[43]}$ Molecular targeted agents other than sorafenib, used in combination or with sorafenib, are being 
investigated and showed encouraging results in phase II studies. Currently several phase III studies evaluating combination of multiple targeted agents for treatments of advanced HCC are ongoing.

In a phase III study, the combination of sorafenib and the EGFR-TKI erlotinib in advanced HCC (SEARCH study) did not significantly improve survival over sorafenib alone. ${ }^{[14]}$ Similarly, the combination of the mTOR inhibitor everolimus with sorafenib did not improve the efficacy of sorafenib in patients with unresectable or metastatic $\mathrm{HCC}^{[44]}$

Refametinib, an oral mitogen-activated protein kinase (MEK), or mitogen-activated protein kinase (MAPK)/ ERK kinase] inhibitor, combined with sorafenib, improved survival in patients with advanced stage HCC (DCR: 43\%, TTP: 122 days, OS: 290 days) with patients with rat sarcoma (RAS) mutations experiencing the best clinical response. However, grades 3 and 4 adverse events were reported in about $80 \%$ of cases. ${ }^{[45]}$ An ongoing trial is evaluating the combination in patients with unresectable or metastatic HCC with RAS mutation (NCT01915602).

Clinical trials of sorafenib in combination with the transforming growth factor receptor beta (TGF- $\beta$ ) inhibitor galunisertib (LY2157299), the mTOR inhibitor temsirolimus, and the histone deacetylase (HDAC) inhibitors vorinostat and resminostat are currently ongoing.

\section{Immune therapy for HCC}

Programmed cell death ligand 1 (PDL-1) are expressed on HCC tumor cells. These interact with PD-1 receptors on activated $T$ cells, leading to their inactivation, thus enhancing tumor-cell survival. Blocking the PDL-1PD-1 receptor interaction increases tumor necrosis. ${ }^{[46]}$

Nivolumab is a fully human IgG4 monoclonal antibody inhibitor of the programmed death-1 (PD-1) receptor that restores T-cell-mediated antitumor activity. Treatment with nivolumab has extended survival in multiple tumor types, and it is approved for metastatic melanoma, metastatic non-small cell lung cancer, advanced renal cell carcinoma, Hodgkin lymphoma, and recurrent or metastatic squamous cell carcinoma of the head and neck. ${ }^{[47]}$

Nivolumab was evaluated in a multiple ascendingdose, phase I/II study in patients with advanced-stage $\mathrm{HCC}$, refusing, intolerant, or progressing on sorafenib with preserved liver function (CTP score up to B7) (Checkmate-040 trial). ${ }^{[48]}$ Patients received intravenous nivolumab $0.1-10 \mathrm{mg} / \mathrm{kg}$ every 2 weeks for up to 2 years, and demonstrated $72 \%$ OS rate at 6 months with durable responses across all dose levels and HCC cohorts (ORR:15\%, DCR: 65\%), with manageable AE profile. These responses were observed regardless of viral hepatitis infection status. In the expansion phase, nivolumab was well tolerated in patients with HBV and $\mathrm{HCV}$ related $\mathrm{HCC}^{\left[{ }^{[8]}\right.}$ OS rates for all patients at 6 and 9 months were $82.5 \%$ and $70.8 \%$, respectively. Disease stabilization was observed in patients who previously progressed on sorafenib, 91 of 204 patients (45\%) had reduction in tumor burden and $45(22 \%)$ had $\geq 30 \%$ reduction in tumor burden compared to baseline. ${ }^{[48]}$ A phase III trial evaluating nivolumab vs. sorafenib as first-line treatment in patients with advanced HCC is ongoing (Checkmate-459, NCT02576509).

Cytotoxic-T-lymphocyte-antigen (CTLA)-4 blockade could be an efficient alternative in advanced HCC. In a phase II study, the CTLA-4 inhibitor tremelimumab showed partial response rate $17.6 \%$, DCR $76 \%$, TTP 6.5 months. ${ }^{[49]}$ However, $45 \%$ of patients experienced grade- 3 aspartate aminotransferase and alanine aminotransferase elevations. Studies exploring combinations of these agents in a randomized, secondline setting are ongoing. A phase II study is currently evaluating the PD-L1 inhibitor durvalumab and tremelimumab alone or in combination for patients with unresectable HCC who progressed on, are intolerant to, or refused treatment with sorafenib (NCT02519348).

\section{Systemic chemotherapy}

Cytotoxic agents as 5-fluorouracil, cisplatin, doxorubicin, gemcitabine, capecitabin, epirubicin or combined regimens showed a low response rate $(<$ $10 \%$ ) with slight improvements in OS. ${ }^{[50,51]}$ Cisplatin, interferon, doxorubicin, and fluorouracil (PIAF) in combination showed favorable results in a phase II study. In a phase III study, PIAF combination compared to doxorubicin alone demonstrated no significant difference in OS (8.67 vs. 6.83 months) or in ORR $(20.9 \%$ vs. $10.5 \%) .{ }^{[51]}$ Patients treated with the PIAF regimen experienced higher rate of myelotoxicity compared with doxorubicin.

The lower effect of doxorubicin in HCC is assumed to result from multidrug resistance (MDR) mechanisms. Doxorubicin-Transdrug (DT), a nano-particle formulation of doxorubicin, has been shown to enter $\mathrm{HCC}$ cells by diffusion, by passing the MDR proteins, and demonstrated higher intracellular concentration and effectiveness than doxorubicin. ${ }^{[52]}$ A phase III multicenter, randomized, controlled trial comparing the efficacy and safety of IV infusions of doxorubicintransdrug in patients with advanced HCC after failure or intolerance to sorafenib (ReLive Study) is ongoing 
(NCT01655693).

S-1, an oral mixture of tegafur, gimeracil and oteracil, that increases the effect of 5 -fluorouracil through increasing its serum concentration while decreasing its gastrointestinal effects, was evaluated as second line therapy in a phase III trial in patients with advanced HCC refractory to sorafenib (S-CUBE). OS was not different from placebo, but PFS was better (80 vs. 42 days). ${ }^{[53]}$

In a phase III study, 371 patients with advanced HCC were randomly assigned to receive either FOLFOX4 (infusional fluorouracil, leucovorin, and oxaliplatin) or doxorubicin (EACH trial). OS was higher in patients who received FOLFOX4 compared to doxorubicin (6.4 vs. 4.97 months, $P=0.07$ ) and reached statistical significance after extension of follow up 7 more months $(P=0.04)$. FOLFOX4 treatment prolonged the median PFS in comparison to doxorubicin (2.93 vs. 1.77 months, $P<0.001)$, the response rate was $8.15 \%$ vs. $2.67 \%(P=0.02)$, and the DCR was $31.55 \%$ vs. $52.17 \%(P<0.0001)$ respectively. ${ }^{[54]}$ FOLFOX4 was well tolerated, although the incidence of neutropenia and neurotoxicity was slightly higher in the FOLFOX4 group.

Oxaliplatin (OXA)-based chemotherapy may be an effective first line treatment for patients with advanced HCC. In a meta-analysis ${ }^{[55]}$ that included 13 studies, 6 studies on gemcitabine, 6 studies on 5 -flurouracil or capecitabine and 1 study on doxorubicin in addition to OXA, the PFS was 3.3 and 4 months in capecitabinebased studies and OXA-based studies, respectively. OS was 6.47 months in capecitabine-based studies compared to 11 months in OXA-based studies. ${ }^{[56]}$

\section{Combination of sorafenib with systemic chemotherapy}

Combination of sorafenib with doxorubicin, ${ }^{[57]}$ octreotide,${ }^{[58]} 5$-fluorouracil, ${ }^{[59]}$ tegafur/uracil, ${ }^{[60]}$ cisplatin and gemcitabine ${ }^{[61]}$ gemcitabine/oxaliplatin $\left(\right.$ GEMOX) ${ }^{[62,63]}$ and capecitabine/oxaliplatin (SECOX) ${ }^{[64]}$ have been investigated [Supplementary Table 3]. Currently, modified FOLFOX plus sorafenib is under investigation (NCT01775501).

A randomized, double-blind phase II trial that included 96 patients with advanced HCC evaluated the efficacy of sorafenib in combination with doxorubicin vs. doxorubicin, and resulted in better OS (13.7 vs. 6.5 months). The median TTP was $6.4 \mathrm{vs} .2 .8$ months, and PFS was 6.0 vs. 2.7 months, respectively. ${ }^{[57]}$ On the other hand, a phase III randomized study of sorafenib plus doxorubicin compared to sorafenib (CALGB 80802) showed higher toxicity for the combination without improvement in OS or PFS. ${ }^{[65]}$

The phase III SILIUS trial included 210 patients with advanced HCC, and compared sorafenib to sorafenib in combination with low dose cisplatin/fluorouracil hepatic arterial infusion chemotherapy (HAIC). OS was equal in both arms (11.8 months). However, sorafenib plus HAIC significantly improved OS in the subset of patients with major portal-vein invasion (11.4 months vs. 6.5 months) ${ }^{[66]}$

\section{LOCOREGIONAL THERAPY}

The presence of portal vein thrombosis (PVT) is a relative contraindication for trans-arterial chemo-embolization (TACE) in most international guidelines, ${ }^{[6,67,68]}$ TACE may be recommended for HCC patients with vascular invasion if radiologic portal invasion is distal to, or in the second-order branches of, the portal vein (Vp1 or Vp2). ${ }^{[69,70]}$ Real life studies have confirmed the safety and efficacy of TACE in patients with PVT. ${ }^{[71]}$

\section{Combination of targeted therapy with loco- regional therapy}

Several studies compared sorafenib plus TACE to sorafenib or TACE ${ }^{[72-78]}$ [Supplementary Table 4]. A meta-analysis of sorafenib in combination with TACE that included data of 1,254 patients found that the combination improved OS and TTP in advanced $\mathrm{HCC}$, but not PFS, with higher rate of severe adverse reaction in the combination group. ${ }^{[79]}$ This combination is being further evaluated in phase III study (STAH trial, NCT01829035) to evaluate combined sorafenib with conventional TACE vs. sorafenib in patients with TACE-refractory and advanced-stage HCC.

Randomized, controlled studies to evaluate the efficacy and safety of sorafenib combined with TACE in advanced HCC patients compared with sorafenib alone (SELECT) (NCT01906216) or TACE alone (NCT02150317) are ongoing. The safety and efficacy of superselective drug-eluting chemoembolization with hepasphere in patients with unresectable advanced HCC is under investigation (SUPER-China, NCT02743065).

A phase II randomized controlled trial (RCT) conducted to explore the efficacy of sorafenib and TACE in advanced HCC patients with major portal vein invasion (NCT01480817) has been terminated and the results are awaited. Combination of TACE with apatinib (NCT03066557) or axitinib (NCT01352728) in patients with advanced HCC are under investigation. Also, comparing TACE plus sunitinib against TACE plus 
placebo (SATURNE) (NCT01164202) is ongoing.

\section{Hepatic arterial infusion chemotherapy}

The Japanese Society of Hepatology and the Korean National Cancer Center both recommend hepatic arterial infusion chemotherapy (HAIC) in their guidelines for management of patients with advanced $\mathrm{HCC}$ and vascular invasion. ${ }^{[69,80,81]}$

In a single-center study in Japan, the HAIC using 5 -fluorouracil and pegylated interferon $\alpha 2 b$ was investigated compared to sorafenib for treatment of advanced HCC. The early ORR was higher in the HAIC group than in the sorafenib group $(71.4 \%$ vs. $10.5 \%, P<0.01)$. The 18 -month survival rate was $55.6 \%$ vs. $16.2 \%, P=0.03$ for the HAIC and sorafenib groups respectively. ${ }^{[82]}$

A multi-center study that included 110 patients with advanced HCC found that HAIC using cisplatin and 5 -fluorouracil with or without epirubicin, demonstrated higher treatment response rate $(24 \%$ vs. $13.3 \%)$ and a better median OS (7.1 vs. 5.5 months) compared to sorafenib. ${ }^{[83]}$ A RCT is recruiting to elucidate the efficacy of HAIC of FOLFOX compared to sorafenib in treatment of advanced HCC (NCT02774187). A phase III randomized open label clinical trial to investigate the efficacy and safety of HAIC (using FOLFOX) compared with TACE in patients with $\mathrm{HCC}$ with major portal venous tumor thrombus is recruiting (NCT02856126).

The efficacy and safety of HAIC with cisplatin and 5 -fluorouracil in patients who have progressed or were intolerant to sorafenib with non-metastatic HCC is being evaluated further, stratified by expression of biomarker predicting therapeutic response is ongoing (the SHINE study, NCT02967887).

\section{Radioembolisation}

Trans-arterial radio-embolization (TARE) using Yttrium-90 spheres is well tolerated with survival rates reported similar to TACE with fewer side effects, better response rate and longer time to progression. ${ }^{[4,84-86]}$ TARE is as safe and effective as sorafenib in advanced-stage HCC. ${ }^{[4,87-90]}$ The median survival with TARE was 13.8 months compared to 10 months with sorafenib $(P>0.05)$, and complete response was only observed in $6.3 \%$ of patients in the TARE group. ${ }^{[1]}$ TARE alone or combined with sorafenib vs. sorafenib in BCLC stage $B$ and $C$ patients are under evaluation (NCT02288507). In a pilot study, sorafenib for 6-8 weeks before Yttrium-90 treatment for patients with unresectable HCC was safe and tolerable. The DCR was $72.4 \%$ and tumor necrosis was observed in $82.8 \%$ of patients. ${ }^{[92]}$
A phase III RCT of Selective Internal Radiation Therapy (SIRT) versus sorafenib in advanced HCC (SIRveNIB) is ongoing (NCT01135056). A study evaluating the monoclonal antibody to PD-1 receptor nivolumab in combination with TARE is under way (NCT02837029). RCTs are ongoing to define the role of TARE as firstline or second-line therapy in advanced HCC.

\section{CONCLUSION}

Sorafenib is still the only approved front-line therapy, and several needs are still unmet and need to be addressed: the combination of local with systemic therapies, the optimal timing of molecular targeted agents in relation to loco-regional treatment, the combinations of systemic targeted therapies, and second-line therapies. Results of recent trials point to several promising therapeutic options: lenvatinib as front-line therapy, and regorafenib and nivolumab as second-line therapy. Several other molecules and combinations are in early stages of development, and more effective therapies will evolve over the next few years. However, improving screening and early detection, and improving access to therapy in limited resource settings are as important in improving global outcome of HCC.

\section{Authors' contributions}

Reviewed the literature and wrote the manuscript: A. Gomaa, I. Waked

\section{Financial support and sponsorship}

None.

\section{Conflict of interest}

There are no conflicts of interest.

\section{Patient consent}

Not applicable.

\section{Ethics approval}

Not applicable.

\section{Supplementary materials}

1. Supplementary Tables $1-4$

2. Supplementary References 1-24

\section{REFERENCES}

1. Global battle against cancer won't be won with treatment alone-effective prevention measures urgently needed to prevent cancer crisis. Cent Eur J Public Health 2014;22:23,28.

2. Llovet JM, Ricci S, Mazzaferro V, Hilgard P, Gane E, Blanc JF, de Oliveira AC, Santoro A, Raoul JL, Forner A. Sorafenib in advanced 
hepatocellular carcinoma. $N$ Engl J Med 2008;359:378-90.

3. Kudo M. A new era of systemic therapy for hepatocellular carcinoma with regorafenib and lenvatinib. Liver Cancer 2017;6:177-84.

4. Sangro B, Inarrairaegui M, Bilbao JI. Radioembolization for hepatocellular carcinoma. J Hepatol 2012;56:464-73.

5. Aerts M, Benteyn D, Van Vlierberghe H, Thielemans K, Reynaert H. Current status and perspectives of immune-based therapies for hepatocellular carcinoma. World J Gastroenterol 2016;22:253-61.

6. Llovet JM, Bustamante J, Castells A, Vilana R, Ayuso MDC, Sala M, Brú C, Rodés J, Bruix J. Natural history of untreated nonsurgical hepatocellular carcinoma: rationale for the design and evaluation of therapeutic trials. Hepatology 1999;29:62-7.

7. Park JW, Chen M, Colombo M, Roberts LR, Schwartz M, Chen PJ, Kudo M, Johnson P, Wagner S, Orsini LS. Global patterns of hepatocellular carcinoma management from diagnosis to death: the BRIDGE Study. Liver Int 2015;35:2155-66.

8. Yang JD, Mohamed EA, Aziz AO, Shousha HI, Hashem MB, Nabeel MM, Abdelmaksoud AH, Elbaz TM, Afihene MY, Duduyemi BM. Characteristics, management, and outcomes of patients with hepatocellular carcinoma in Africa: a multicountry observational study from the Africa Liver Cancer Consortium. Lancet Gastroenterol Hepatol 2017;2:103-11.

9. Cervello M, McCubrey JA, Cusimano A, Lampiasi N, Azzolina A, Montalto G. Targeted therapy for hepatocellular carcinoma: novel agents on the horizon. Oncotarget 2012;3:236-60.

10. Nojiri K, Sugimoto K, Shiraki K, Tameda M, Inagaki Y, Ogura S, Kasai C, Kusagawa S, Yoneda M, Yamamoto N. Sorafenib and TRAIL have synergistic effect on hepatocellular carcinoma. Int J Oncol 2013;42:101-8.

11. Cheng AL, Kang YK, Chen Z, Tsao CJ, Qin S, Kim JS, Luo R, Feng J, Ye S, Yang TS. Efficacy and safety of sorafenib in patients in the Asia-Pacific region with advanced hepatocellular carcinoma: a phase III randomised, double-blind, placebo-controlled trial. Lancet Oncol 2009;10:25-34.

12. Cheng AL, Kang YK, Lin DY, Park JW, Kudo M, Qin S, Chung HC, Song X, Xu J, Poggi G. Sunitinib versus sorafenib in advanced hepatocellular cancer: results of a randomized phase III trial. J Clin Oncol 2013;31:4067-75.

13. Johnson PJ, Qin S, Park JW, Poon RT, Raoul JL, Philip PA, Hsu CH, $\mathrm{Hu} \mathrm{TH}, \mathrm{Heo} \mathrm{J}, \mathrm{Xu}$ J. Brivanib versus sorafenib as first-line therapy in patients with unresectable, advanced hepatocellular carcinoma: results from the randomized phase III BRISK-FL study. J Clin Oncol 2013;31:3517-24.

14. Zhu AX, Rosmorduc O, Evans TJ, Ross PJ, Santoro A, Carrilho FJ, Bruix J, Qin S, Thuluvath PJ, Llovet JM. SEARCH: a phase III, randomized, double-blind, placebo-controlled trial of sorafenib plus erlotinib in patients with advanced hepatocellular carcinoma. J Clin Oncol 2015;33:559-66.

15. Cainap C, Qin S, Huang WT, Chung IJ, Pan H, Cheng Y, Kudo M, Kang YK, Chen PJ, Toh HC. Linifanib versus sorafenib in patients with advanced hepatocellular carcinoma: results of a randomized phase III trial. J Clin Oncol 2015;33:172-9.

16. Cheng AL, Thongprasert S, Lim HY, Sukeepaisarnjaroen W, Yang TS, Wu CC, Chao Y, Chan SL, Kudo M, Ikeda M. Randomized, open-label phase 2 study comparing frontline dovitinib versus sorafenib in patients with advanced hepatocellular carcinoma. Hepatology 2016;64:774-84.

17. Iavarone M, Cabibbo G, Piscaglia F, Zavaglia C, Grieco A, Villa E, Cammà C, Colombo M. Field-practice study of sorafenib therapy for hepatocellular carcinoma: a prospective multicenter study in Italy. Hepatology 2011;54:2055-63.

18. Lencioni R, Kudo M, Ye SL, Bronowicki JP, Chen XP, Dagher L,
Furuse J, Geschwind J, Guevara LL, Papandreou C. GIDEON (Global Investigation of therapeutic DEcisions in hepatocellular carcinoma and of its treatment with sorafeNib): second interim analysis. Int $J$ Clin Pract 2014;68:609-17.

19. Llovet JM, Peña CE, Lathia CD, Shan M, Meinhardt G, Bruix J. Plasma biomarkers as predictors of outcome in patients with advanced hepatocellular carcinoma. Clin Cancer Res 2012;18:2290-300.

20. Vincenzi B, Santini D, Russo A, Addeo R, Giuliani F, Montella L, Rizzo S, Venditti O, Frezza AM, Caraglia M. Early skin toxicity as a predictive factor for tumor control in hepatocellular carcinoma patients treated with sorafenib. Oncologist 2010;15:85-92.

21. Otsuka T, Eguchi Y, Kawazoe S, Yanagita K, Ario K, Kitahara K, Kawasoe H, Kato H, Mizuta T. Skin toxicities and survival in advanced hepatocellular carcinoma patients treated with sorafenib. Hepatol Res 2012;42:879-86.

22. Reig M, Torres F, RodriguezLope C, Forner A, LLarch N, Rimola J, Darnell A, Ríos J, Ayuso C, Bruix J. Early dermatologic adverse events predict better outcome in HCC patients treated with sorafenib. J Hepatol 2014;61:318-24.

23. Koschny R, Gotthardt D, Koehler C, Jaeger D, Stremmel W, Ganten TM. Diarrhea is a positive outcome predictor for sorafenib treatment of advanced hepatocellular carcinoma. Oncology 2013;84:6-13.

24. Estfan B, Byrne M, Kim R. Sorafenib in advanced hepatocellular carcinoma: hypertension as a potential surrogate marker for efficacy. Am J Clin Oncol 2013;36:319-24.

25. Pinter M, Sieghart W, Graziadei I, Vogel W, Maieron A, Königsberg R, Weissmann A, Kornek G, Plank C, Peck-Radosavljevic M. Sorafenib in unresectable hepatocellular carcinoma from mild to advanced stage liver cirrhosis. Oncologist 2009;14:70-6.

26. Iavarone M, Cabibbo G, Biolato M, Della Corte C, Maida M, Barbara M, Basso M, Vavassori S, Craxì A, Grieco A. Predictors of survival in patients with advanced hepatocellular carcinoma who permanently discontinued sorafenib. Hepatology 2015;62:784-91.

27. Reig M, Rimola J, Torres F, Darnell A, RodriguezLope C, Forner A, LLarch N, Ríos J, Ayuso C, Bruix J. Postprogression survival of patients with advanced hepatocellular carcinoma: rationale for second-line trial design. Hepatology 2013;58:2023-31.

28. Finn RS, Cheng AL, Ikeda K, Kudo M, Tamai T, Dutcus CE, Younger S, Han KH, Qin S, Raymond E. A multicenter, open-label, phase 3 trial to compare the efficacy and safety of lenvatinib (E7080) versus sorafenib in first-line treatment of subjects with unresectable hepatocellular carcinoma. J Clin Oncol 2014;32 suppl:tps4153.

29. Bruix J, Qin S, Merle P, Granito A, Huang YH, Bodoky G, Pracht M, Yokosuka O, Rosmorduc O, Breder V. Regorafenib for patients with hepatocellular carcinoma who progressed on sorafenib treatment (RESORCE): a randomised, double-blind, placebo-controlled, phase 3 trial. Lancet 2017;389:56-66.

30. Ikeda K, Kudo M, Kawazoe S, Osaki Y, Ikeda M, Okusaka T, Tamai T, Suzuki T, Hisai T, Hayato S. Phase 2 study of lenvatinib in patients with advanced hepatocellular carcinoma. J Gastroenterol 2017;52:512-9.

31. Positive Topline Results of Large Phase 3 Trial Show Eisai's Lenvatinib Meets Primary Endpoint in Unresectable Hepatocellular Carcinoma. Available from: http://eisai.mediaroom.com/201701-25-Positive-Topline-Results-of-Large-Phase-3-Trial-ShowEisais-Lenvatinib-Meets-Primary-Endpoint-in-UnresectableHepatocellular-Carcinoma. [Last accessed on June 1, 2017].

32. Zhu AX, Park JO, Ryoo BY, Yen CJ, Poon R, Pastorelli D, Blanc JF, Chung HC, Baron AD, Pfiffer TE, Okusaka T, Kubackova K, Trojan J, Sastre J, Chau I, Chang SC, Abada PB, Yang L, Schwartz JD, Kudo M. Ramucirumab versus placebo as second-line treatment in patients with advanced hepatocellular carcinoma following first-line therapy 
with sorafenib (REACH): a randomised, double-blind, multicentre, phase 3 trial. Lancet Oncol 2015;16:859-70.

33. Zhu AX, Kudo M, Assenat E, Cattan S, Kang YK, Lim HY, Poon RT, Blanc JF, Vogel A, Chen CL. Effect of everolimus on survival in advanced hepatocellular carcinoma after failure of sorafenib: the EVOLVE-1 randomized clinical trial. JAMA 2014;312:57-67.

34. Llovet JM, Decaens T, Raoul JL, Boucher E, Kudo M, Chang C, Kang YK, Assenat E, Lim HY, Boige V. Brivanib in patients with advanced hepatocellular carcinoma who were intolerant to sorafenib or for whom sorafenib failed: results from the randomized phase III BRISK-PS study. J Clin Oncol 2013;31:3509-16.

35. Bruix J, Sherman M. Management of hepatocellular carcinoma: an update. Hepatology 2011;53:1020-2.

36. Strumberg D, Schultheis B. Regorafenib for cancer. Expert Opin Investig Drugs 2012;21:879-89.

37. Santoro A, Rimassa L, Borbath I, Daniele B, Salvagni S, Van Laethem JL, Van Vlierberghe H, Trojan J, Kolligs FT, Weiss A. Tivantinib for second-line treatment of advanced hepatocellular carcinoma: a randomised, placebo-controlled phase 2 study. Lancet Oncol 2013;14:55-63.

38. Zhu AX, Ryoo BY, Yen CJ, Kudo M, Poon RT-P, Pastorelli D, Blanc JF, Chung HC, Baron AD, Pfiffer TEF. Ramucirumab (RAM) as second-line treatment in patients (pts) with advanced hepatocellular carcinoma (HCC): analysis of patients with elevated $\alpha$-fetoprotein (AFP) from the randomized phase III REACH study. Am Soc Clinl Oncol 2015;35:abstr4108.

39. Zhu AX, Baron AD, Malfertheiner P, Kudo M, Kawazoe S, Pezet D, Weissinger F, Brandi G, Barone CA, Okusaka T. Ramucirumab as second-line treatment in patients with advanced hepatocellular carcinoma: analysis of REACH trial results by Child-Pugh score. JAMA Oncol 2017;3:235-43.

40. Finn RS. Current and future treatment strategies for patients with advanced hepatocellular carcinoma: role of mTOR inhibition. Liver Cancer 2012;1:247-56.

41. Kang YK, Yau T, Park JW, Lim H, Lee TY, Obi S, Chan S, Qin S, Kim R, Casey M. Randomized phase II study of axitinib versus placebo plus best supportive care in second-line treatment of advanced hepatocellular carcinoma. Ann Oncol 2015;26:2457-63.

42. Qin S. Apatinib in Chinese patients with advanced hepatocellular carcinoma: a phase II randomized, open-label trial. Am Soc Clin Oncol 2014;32 suppl:abstr4019.

43. O'Reilly KE, Rojo F, She Q-B, Solit D, Mills GB, Smith D, Lane H, Hofmann F, Hicklin DJ, Ludwig DL. mTOR inhibition induces upstream receptor tyrosine kinase signaling and activates Akt. Cancer Res 2006;66:1500-8.

44. Koeberle D, Dufour JF, Demeter G, Li Q, Ribi K, Samaras P, Saletti P, Roth A, Horber D, Buehlmann M. Sorafenib with or without everolimus in patients with advanced hepatocellular carcinoma (HCC): a randomized multicenter, multinational phase II trial (SAKK 77/08 and SASL 29). Ann Oncol 2016;27:856-61.

45. Lim HY, Heo J, Choi HJ, Lin CY, Yoon JH, Hsu C, Rau KM, Poon RT, Yeo W, Park JW. A phase II study of the efficacy and safety of the combination therapy of the MEK inhibitor refametinib (BAY 86-9766) plus sorafenib for Asian patients with unresectable hepatocellular carcinoma. Clin Cancer Res 2014;20:5976-85.

46. Okazaki T, Honjo T. PD-1 and PD-1 ligands: from discovery to clinical application. Int Immunol 2007;19:813-24.

47. Brahmer JR, Hammers H, Lipson EJ. Nivolumab: targeting PD-1 to bolster antitumor immunity. Future Oncol 2015;11:1307-26.

48. Melero I, Sangro B, Yau TC, Hsu C, Kudo M, Crocenzi TS, Kim TY, Choo S, Trojan J, Meyer T, Welling TH, Yeo W, Chopra A, Anderson J, Dela Cruz CM, Lang L, Jaclyn N, Tang H, El-
Khoueiry A. Nivolumab dose escalation and expansion in patients with advanced hepatocellular carcinoma (HCC): the CheckMate 040 study. Available from: https://www.mdlinx.com/gastroenterology/ conference-abstract.cfm/60392/?nonus $=0 \&$ searchstring $=\&$ coverage day $=0$ \&page $=2$. [Last accessed on June 1, 2017].

49. Sangro B, Gomez-Martin C, de la Mata M, Iñarrairaegui $M$, Garralda E, Barrera P, Riezu-Boj JI, Larrea E, Alfaro C, Sarobe P. A clinical trial of CTLA-4 blockade with tremelimumab in patients with hepatocellular carcinoma and chronic hepatitis C. $J$ Hepatol 2013;59:81-8.

50. Fuchs CS, Clark JW, Ryan DP, Kulke MH, Kim H, Earle CC, Vincitore M, Mayer RJ, Stuart KE. A phase II trial of gemcitabine in patients with advanced hepatocellular carcinoma. Cancer 2002;94:3186-91.

51. Yeo W, Mok TS, Zee B, Leung TW, Lai PB, Lau WY, Koh J, Mo FK, Yu SC, Chan AT, Hui P, Ma B, Lam KC, Ho WM, Wong HT, Tang A, Johnson PJ. A randomized phase III study of doxorubicin versus cisplatin/interferon alpha-2b/doxorubicin/fluorouracil (PIAF) combination chemotherapy for unresectable hepatocellular carcinoma. J Natl Cancer Inst 2005;97:1532-8.

52. de Verdi Ã A. Reversion of multidrug resistance with polyalkylcyanoacrylate nanoparticles: towards a mechanism of action. Br J Cancer 1997;76:198.

53. Kudo M, Moriguchi M, Numata K, Hidaka H, Tanaka H, Ikeda M, Kawazoe S, Ohkawa S, Sato Y, Kaneko S, Furuse J, Takeuchi M, Fang X, Date Y, Takeuchi M, Okusaka T. S-1 versus placebo in patients with sorafenib-refractory advanced hepatocellular carcinoma (S-CUBE): a randomised, double-blind, multicentre, phase 3 trial. Lancet Gastroenterol Hepatol 2017;2:407-17.

54. Qin S, Bai Y, Lim HY, Thongprasert S, Chao Y, Fan J, Yang TS, Bhudhisawasdi V, Kang WK, Zhou Y. Randomized, multicenter, open-label study of oxaliplatin plus fluorouracil/leucovorin versus doxorubicin as palliative chemotherapy in patients with advanced hepatocellular carcinoma from Asia. J Clin Oncol 2013;31:3501-8.

55. Liu L, Zheng Y, Han L, Qin S. Efficacy and safety of oxaliplatinbased chemotherapy for advanced primary hepatic carcinoma: a systemic review and meta analysis of prospective studies. Linchuang Zhongliuxue Zazhi 2015;20:769-79.

56. Petrelli F, Coinu A, Borgonovo K, Cabiddu M, Ghilardi M, Lonati V, Barni S. Oxaliplatin-based chemotherapy: a new option in advanced hepatocellular carcinoma. a systematic review and pooled analysis. Clin Oncol 2014;26:488-96.

57. Abou-Alfa GK, Johnson P, Knox JJ, Capanu M, Davidenko I, Lacava J, Leung T, Gansukh B, Saltz LB. Doxorubicin plus sorafenib vs doxorubicin alone in patients with advanced hepatocellular carcinoma: a randomized trial. JAMA 2010;304:2154-60.

58. Del Prete S, Montella L, Caraglia M, Maiorino L, Cennamo G, Montesarchio V, Piai G, Febbraro A, Tarantino L, Capasso E. Sorafenib plus octreotide is an effective and safe treatment in advanced hepatocellular carcinoma: multicenter phase II So. LAR. study. Cancer Chemother Pharmacol 2010;66:837-44.

59. Petrini I, Lencioni M, Ricasoli M, Iannopollo M, Orlandini C, Oliveri F, Bartolozzi C, Ricci S. Phase II trial of sorafenib in combination with 5-fluorouracil infusion in advanced hepatocellular carcinoma. Cancer Chemother Pharmacol 2012;69:773-80.

60. Hsu CH, Shen YC, Lin ZZ, Chen PJ, Shao YY, Ding YH, Hsu C, Cheng AL. Phase II study of combining sorafenib with metronomic tegafur/uracil for advanced hepatocellular carcinoma. J Hepatol 2010;53:126-31.

61. Giuliani F, Febbraro A, Addeo R, Rizzi Jr D, Maiello E, Del Prete S, Pisconti S, Colucci G. Sorafenib plus cisplatin and gemcitabine in the treatment of advanced hepatocellular carcinoma (HCC): a phase II 
study by the Gruppo Oncologico dell'Italia Meridionale (prot. GOIM 2705). J Clin Oncol 2011;29:225.

62. Liu Y, Yue H, Xu S, Wang F, Ma N, Li K, Qiao L, Wang J. Firstline gemcitabine and oxaliplatin (GEMOX) plus sorafenib, followed by sorafenib as maintenance therapy, for patients with advanced hepatocellular carcinoma: a preliminary study. Int J Clin Oncol 2015;20:952-9.

63. Assenat E, Boige V, Thezenas S, Pageaux GP, Peron JM, Becouarn Y, Dahan L, Merle P, Blanc JF, Bouche O, Ramdani M, Mazard T, Bleuse JP, Ychou M. Sorafenib (S) alone versus S combined with gemcitabine and oxaliplatin (GEMOX) in first-line treatment of advanced hepatocellular carcinoma (HCC): final analysis of the randomized phase II GONEXT trial (UNICANCER/FFCD PRODIGE 10 trial). J Clin Oncol 2013;31 suppl 15:abstr4028.

64. Yau T, Cheung FY, Lee F, Choo SP, Wong H, Toh HC, Leung A, Chan P, Yau T, Wong J. A multicenter phase II study of sorafenib, capecitabine, and oxaliplatin (SECOX) in patients with advanced hepatocellular carcinoma: final results of Hong Kong-Singapore Hepatocellular Carcinoma Research Collaborative Group study. J Clin Oncol 2013;31 suppl 15:abstr4117.

65. Abou-Alfa GK, Niedzwieski D, Knox JJ, Kaubisch A, Posey J, Tan BR, Kavan P, Goel R, Murray JJ, Bekaii-Saab TS. Phase III randomized study of sorafenib plus doxorubicin versus sorafenib in patients with advanced hepatocellular carcinoma (HCC): CALGB80802 (Alliance). Am Soc Clin Oncol 2016;suppl 4:abstr192.

66. Kudo M, Ueshima K, Yokosuka O, Obi S, Izumi N, Aikata H, Nagano H, Hatano E, Sasaki Y, Hino K. Prospective randomized controlled phase III trial comparing the efficacy of sorafenib versus sorafenib in combination with low-dose cisplatin/fluorouracil hepatic arterial infusion chemotherapy in patients with advanced hepatocellular carcinoma. J Hepatol 2016;64:S209-10.

67. EASL-EORTC clinical practice guidelines: management of hepatocellular carcinoma. J Hepatol 2012;56:908-43.

68. Bruix J, Sherman M. Management of hepatocellular carcinoma. Hepatology 2005;42:1208-36.

69. Kokudo N, Hasegawa K, Akahane M, Igaki H, Izumi N, Ichida T, Uemoto S, Kaneko S, Kawasaki S, Ku Y. Evidence-based clinical practice guidelines for hepatocellular carcinoma: the Japan society of hepatology 2013 update (3rd JSH-HCC guidelines). Hepatol Res 2015;45:238-46.

70. Kudo M, Izumi N, Kokudo N, Matsui O, Sakamoto M, Nakashima O, Kojiro M, Makuuchi M; HCC Expert Panel of Japan Society of Hepatology. Management of hepatocellular carcinoma in Japan: consensus-based clinical practice guidelines proposed by the Japan Society of Hepatology (JSH) 2010 updated version. Dig Dis 2011;29:339-64.

71. Chung GE, Lee JH, Kim HY, Hwang SY, Kim JS, Chung JW, Yoon JH, Lee HS, Kim YJ. Transarterial chemoembolization can be safely performed in patients with hepatocellular carcinoma invading the main portal vein and may improve the overall survival. Radiology 2011;258:627-34.

72. Martin R, Keck G, Robbins K, Strnad B, Dubel G, Longares J, Padr R, Narayanan G. Evaluation of sorafenib in combination with doxorubicin-loaded DC bead as a combination treatment option for HCC. ASCO Gastrointestinal Cancers Symposium 2010;suppl:abstr 216.

73. Muhammad A, Dhamija M, Vidyarthi G, Amodeo D, Boyd W, Miladinovic B, Kumar A. Comparative effectiveness of traditional chemoembolization with or without sorafenib for hepatocellular carcinoma. World J Hepatol 2013;5:364-71.

74. Bai W, Wang YJ, Zhao Y, Qi XS, Yin ZX, He CY, Li RJ, Wu KC, Xia JL, Fan DM, Han GH. Sorafenib in combination with transarterial chemoembolization improves the survival of patients with unresectable hepatocellular carcinoma: a propensity score matching study. J Dig Dis 2013;14:181-90.

75. Choi GH, Shim JH, Kim MJ, Ryu MH, Ryoo BY, Kang YK, Shin YM, Kim KM, Lim YS, Lee HC. Sorafenib alone versus sorafenib combined with transarterial chemoembolization for advanced-stage hepatocellular carcinoma: results of propensity score analyses. Radiology 2013;269:603-11.

76. Qu XD, Chen CS, Wang JH, Yan ZP, Chen JM, Gong GQ, Liu QX, Luo JJ, Liu LX, Liu R, Qian S. The efficacy of TACE combined sorafenib in advanced stages hepatocellullar carcinoma. BMC Cancer 2012;12:263.

77. Ohki T, Sato K, Yamagami M, Ito D, Yamada T, Kawanishi K, Kojima K, Seki M, Toda N, Tagawa K. Efficacy of transcatheter arterial chemoembolization followed by sorafenib for intermediate/ advanced hepatocellular carcinoma in patients in Japan: a retrospective analysis. Clin Drug Investig 2015;35:751-9.

78. Hu H, Duan Z, Long X, Hertzanu Y, Shi H, Liu S, Yang Z. Sorafenib combined with transarterial chemoembolization versus transarterial chemoembolization alone for advanced-stage hepatocellular carcinoma: a propensity score matching study. PLoS One 2014;9:e96620.

79. Zhang L, Hu P, Chen X, Bie P. Transarterial chemoembolization (TACE) plus sorafenib versus TACE for intermediate or advanced stage hepatocellular carcinoma: a meta-analysis. PLoS One 2014;9:e100305.

80. Kudo M, Matsui O, Izumi N, Iijima H, Kadoya M, Imai Y, Okusaka T, Miyayama S, Tsuchiya K, Ueshima K. JSH consensus-based clinical practice guidelines for the management of hepatocellular carcinoma: 2014 update by the Liver Cancer Study Group of Japan. Liver Cancer 2014;3:458-68.

81. Group KLCS. 2014 Korean Liver Cancer Study Group-National Cancer Center Korea practice guideline for the management of hepatocellular carcinoma. Ko J Radiol 2015;16:465-522.

82. Kasai K, Sawara K, Suzuki K. Combination therapy of intra-arterial 5-fluorouracil and systemic pegylated interferon alpha-2b for advanced hepatocellular carcinoma. Int J Clin Oncol 2011;16:221-9.

83. Song DS, Song MJ, Bae SH, Chung WJ, Jang JY, Kim YS, Lee SH, Park JY, Yim HJ, Cho SB, Park SY, Yang JM. A comparative study between sorafenib and hepatic arterial infusion chemotherapy for advanced hepatocellular carcinoma with portal vein tumor thrombosis. J Gastroenterol 2015;50:445-54.

84. Salem R, Mazzaferro V, Sangro B. Yttrium 90 radioembolization for the treatment of hepatocellular carcinoma: biological lessons, current challenges, and clinical perspectives. Hepatology 2013;58:2188-97.

85. Salem R, Lewandowski RJ, Mulcahy MF, Riaz A, Ryu RK, Ibrahim S, Atassi B, Baker T, Gates V, Miller FH, Sato KT, Wang E, Gupta R, Benson AB, Newman SB, Omary RA, Abecassis M, Kulik L. Radioembolization for hepatocellular carcinoma using Yttrium-90 microspheres: a comprehensive report of long-term outcomes. Gastroenterology 2010;138:52-64.

86. Salem R, Lewandowski RJ, Kulik L, Wang E, Riaz A, Ryu RK, Sato KT, Gupta R, Nikolaidis P, Miller FH, Yaghmai V, Ibrahim SM, Senthilnathan S, Baker T, Gates VL, Atassi B, Newman S, Memon K, Chen R, Vogelzang RL, Nemcek AA, Resnick SA, Chrisman HB, Carr J, Omary RA, Abecassis M, Benson AB 3rd, Mulcahy MF. Radioembolization results in longer time-to-progression and reduced toxicity compared with chemoembolization in patients with hepatocellular carcinoma. Gastroenterology 2011;140:497-507.

87. Sangro B, Carpanese L, Cianni R, Golfieri R, Gasparini D, Ezziddin S, Paprottka PM, Fiore F, Van Buskirk M, Bilbao JI, Ettorre GM, Salvatori R, Giampalma E, Geatti O, Wilhelm K, Hoffmann RT, Izzo F, Inarrairaegui M, Maini CL, Urigo C, Cappelli A, Vit A, Ahmadzadehfar H, Jakobs TF, Lastoria S. Survival after yttrium-90 
resin microsphere radioembolization of hepatocellular carcinoma across Barcelona clinic liver cancer stages: a European evaluation. Hepatology 2011;54:868-78.

88. Mazzaferro V, Sposito C, Bhoori S, Romito R, Chiesa C, Morosi C, Maccauro M, Marchianò A, Bongini M, Lanocita R. Yttrium-90 radioembolization for intermediate-advanced hepatocellular carcinoma: a phase 2 study. Hepatology 2013;57:1826-37.

89. Kulik LM, Carr BI, Mulcahy MF, Lewandowski RJ, Atassi B, Ryu RK, Sato KT, Benson A, Nemcek AA, Gates VL. Safety and efficacy of $90 \mathrm{Y}$ radiotherapy for hepatocellular carcinoma with and without portal vein thrombosis. Hepatology 2008;47:71-81.

90. Gramenzi A, Golfieri R, Mosconi C, Cappelli A, Granito A,
Cucchetti A, Marinelli S, Pettinato C, Erroi V, Fiumana S. Yttrium-90 radioembolization vs sorafenib for intermediate-locally advanced hepatocellular carcinoma: a cohort study with propensity score analysis. Liver Int 2015;35:1036-47.

91. Cho YY, Lee M, Kim HC, Chung JW, Kim YH, Gwak GY, Bae $\mathrm{SH}$, Heo J, Kim YJ. Radioembolization is a safe and effective treatment for hepatocellular carcinoma with portal vein thrombosis: a propensity score analysis. PLoS One 2016;11:e0154986.

92. Salman A, Simoneau E, Hassanain M, Chaudhury P, Boucher LM, Valenti D, Cabrera T, Nudo C, Metrakos P. Combined sorafenib and yttrium-90 radioembolization for the treatment of advanced hepatocellular carcinoma. Curr Oncol 2016;23:e472-80. 